\title{
Fuzzy Neural Optimized Fuzzy Logic Controller Based Dynamic Voltage Restorer for Power Quality Improvement with Non-linear Loads
}

\author{
Samhar Saeed Shukir \\ Electrical Department, Technical Institute - Kut, Middle Technical University, Baghdad, Iraq
}

Email address:

samharalwandi@gmail.com

\section{To cite this article:}

Samhar Saeed Shukir. Fuzzy Neural Optimized Fuzzy Logic Controller Based Dynamic Voltage Restorer for Power Quality Improvement with Non-linear Loads. International Journal of Engineering Management. Vol. 5, No. 1, 2021, pp. 21-32. doi: 10.11648/j.ijem.20210501.13

Received: March 26, 2021; Accepted: April 22, 2021; Published: April 30, 2021

\begin{abstract}
Recently a large attention has been focused on a power quality domain due to: disturbances caused by non-linear loads, Increase in number of electronic devices and growth of renewable energy sources. Power quality measures the fitness of electric power transmitted from generation to industrial, domestic and commercial consumers. At least $50 \%$ of power quality problems are of voltage quality type. In power system voltage sags, voltage distortion introduced by harmonics, and asymmetrical voltage are considered to be the most severe affecting power quality, because both utilities and consumers are affected by these disturbances. Different methods introduced to solve power problems but the custom power devices are the most effective and efficient methods, one of which is the use of the Dynamic Voltage Restorer (DVR). The main objectives of this research are to achieve more accuracy in compensating the voltage variations and reducing the total harmonics distortion (THD) to acceptable limits. Most of the researchers applied the control strategies to compensate the voltage disturbances in critical load but did not focus on the objective of reducing the total harmonics distortion (THD). In many sensitive loads such as, airport lighting system, medical equipment, auxiliary plant of power system, and adjustable speed drives., the level of the (THD) is more important, this research focuses on mitigating the harmonics to less than $3 \%$. An adaptive controller like fuzzy neural optimized fuzzy logic controller is proposed to improve the performance of the DVR in injecting the required voltage to restore the load voltage to its nominal value under different voltage variations which are created by MATLAB/SIMULINK program for a period of $0.15 \mathrm{~s}$ from $0.8 \mathrm{~s}$ and kept till $0.95 \mathrm{~s}$.
\end{abstract}

Keywords: Dynamic Voltage Restorer, Power Quality Improvement, Artificial Intelligent, Fuzzy Neural Optimized Fuzzy Logic Controller

\section{Introduction}

The power quality problems can be defined as the difference between the quality of power supplied and the quality of power required [1]. Power quality is not only a technical problem but also a problem that leads to financial losses. Many surveys have been shown that poor power quality causes large economic losses to industrial sectors and a large amount of power is wasted due to poor power quality in the services [2]. A survey conducted on industrial sector in India shows that the poor power quality and operating conditions related to downtime lead to losses of estimated ten billion USD [3]. Voltage sag, harmonics, and asymmetrical voltage are the most common power quality problems in the industrial process as shown in Figure 1.

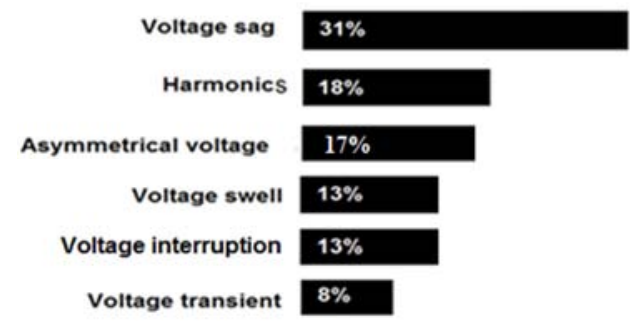

Figure 1. Classification of power quality problems [4].

Sag is a sudden decrease in the r.m.s voltage and make it between $10 \%$ and $90 \%$ from its nominal value and lasting 
from 0.5 cycle to several seconds it can be symmetrical or unsymmetrical, a three phase fault produces a symmetrical sag while single line to ground fault and double line to ground fault cause unsymmetrical sag. The main reasons of sag are: faults, recloser of circuit breaker, energizing several transformers at the same time, and starting of induction motors. Voltage sag pose a serious power quality issues for the electric power industry and leads to the damage of sensitivity equipment such as; programmable logic computer (PLC), computers, motor starter contactors, and adjustable speed drives (ASD). Sag problems in industrial equipments include; unnecessary work for voltage sensors, incorrect reports from sensors such as water pressure sensors and air flow sensors, and fuses, relays and circuit breaker operating due to a large increase in the current after the sag [5]. Harmonics is the presence of spectral components whose frequencies are multiplies the fundamental frequency. Harmonics occur due to, the voltage generated by synchronous generators are not exactly sine wave due to the deviation from the ideal form of generators, the electrical power transmitted from generating stations to the load is not completely linear for number of reasons such as nonlinear power transformers due to the saturation of magnetic flux in the iron core of the transformer, and transformation from $\mathrm{AC}$ voltage to $\mathrm{DC}$ voltage and vice versa occur using power electronic components [6]. According to IEEE standards for the system of less than $69 \mathrm{kV}$ the harmonics distortion limits are 3\% for individual voltage and 5\% for total harmonics distortion [7]. Harmonics cause overheating, overloading, and additional losses to the transformers, motors, and other power system equipments. Asymmetrical voltage occurs if the individual phase voltages are not equal or the phase relationship is not 120 degrees. Asymmetrical voltage happens due to a large single loads such as induction furnaces and also occurs due to the unbalance loading for the individual phase voltages. Several types of power improvement devices have been developed to protect equipments from power problems, but the efficient and effective devices are custom power devices which are able to provide customized solutions to power quality variations. The notion of custom power devices, is using power electronic controllers in the power systems to supply high quality power and reliable that is needed for the sensitive equipments. The custom power devices can be classified into two categories: Network reconfiguring type and Compensating type [8]. Network reconfiguring type protects the sensitive loads by; Avoid interruption, voltage sag, and swell by connecting healthy feeder, Disconnects the fault circuits, Limits the fault current by quickly inserting a series inductance in the fault path. The compensating type is used for load balancing and active filtering, power factor correction, and voltage regulation. Compensating type are Dynamic Voltage Restorer (DVR), Unified Power Quality Conditioner (UPQC) and Distributed Static Compensator (DSTATCOM). Dynamic Voltage Restorer (DVR) is a series device and it is effective and efficient in compensating large voltage variations by voltage injection. It is used for mitigating the power disturbances [8]. The connection of the DVR with system is depicted in figure 2 .

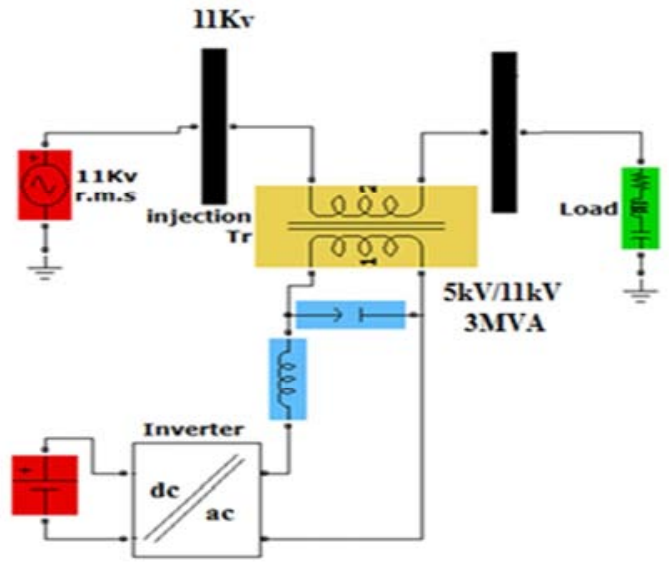

Figure 2. The connection of the DVR with power system.

Distributed Static Compensator (DSTATCOM) is a shunt device to compensate small voltage variations by current injection which is very difficult to achieve because the supply impedance is low and the injected current has to be high to increase the load voltage. DSTATCOM is larger in size and costs more compared with the DVR [9]. The connection of the DSTATCOM is shown in figure 3.

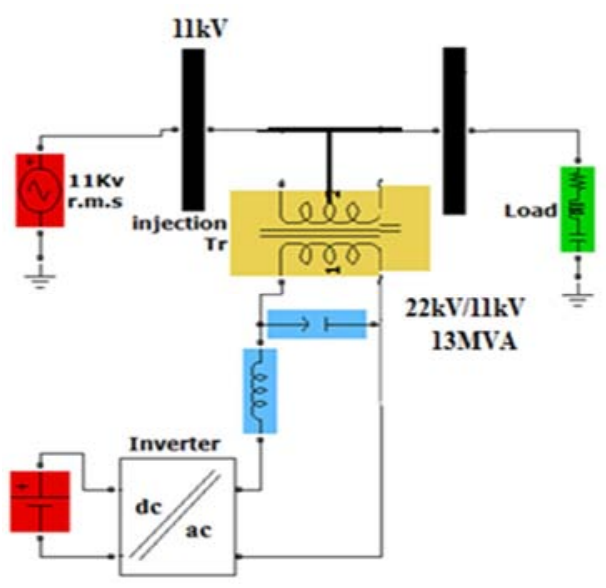

Figure 3. The connection of the DSTATCOM with power system.

Unified Power Quality Conditioner (UPQC) is a combination of series (DVR) and shunt (DSTATCOM) connected together by a common DC link capacitor. Combining the series/shunt controllers improve the performance but with higher costs [10]. The connection of the UPQC is demonstrated in figure 4.

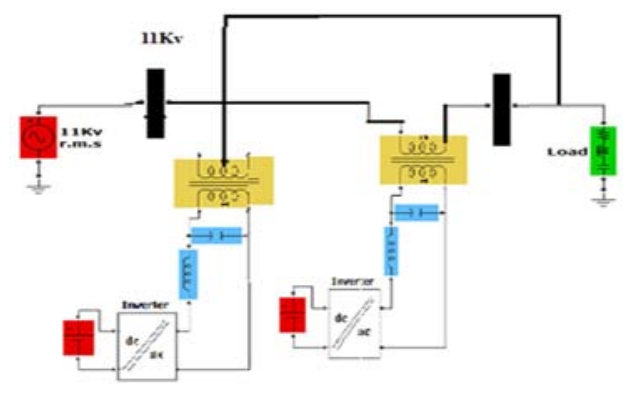

Figure 4. The connection of the UPQC with power system. 
Hence, the Dynamic Voltage Restorer is considered as a power efficient device in mitigating the sag problem compared to other custom power devices. DVR is designed for large loads ranging from a few MVA to 50 MVA or higher [11]. For improving the performance of the DVR several studies have been conducted, which are shown that the Artificial Intelligent controller for the DVR is efficient and powerful in eliminating the power quality problems, because the inverter in the DVR is non-linear and needs a non-linear controller. Simulation results show the ability of the DVR based on fuzzy neural optimized fuzzy logic controller in treating and keeping the load voltage constant and balance under different power disturbances and fault conditions.

\section{The Structure of the DVR}

The basic configuration of the DVR is shown in Figure 5.

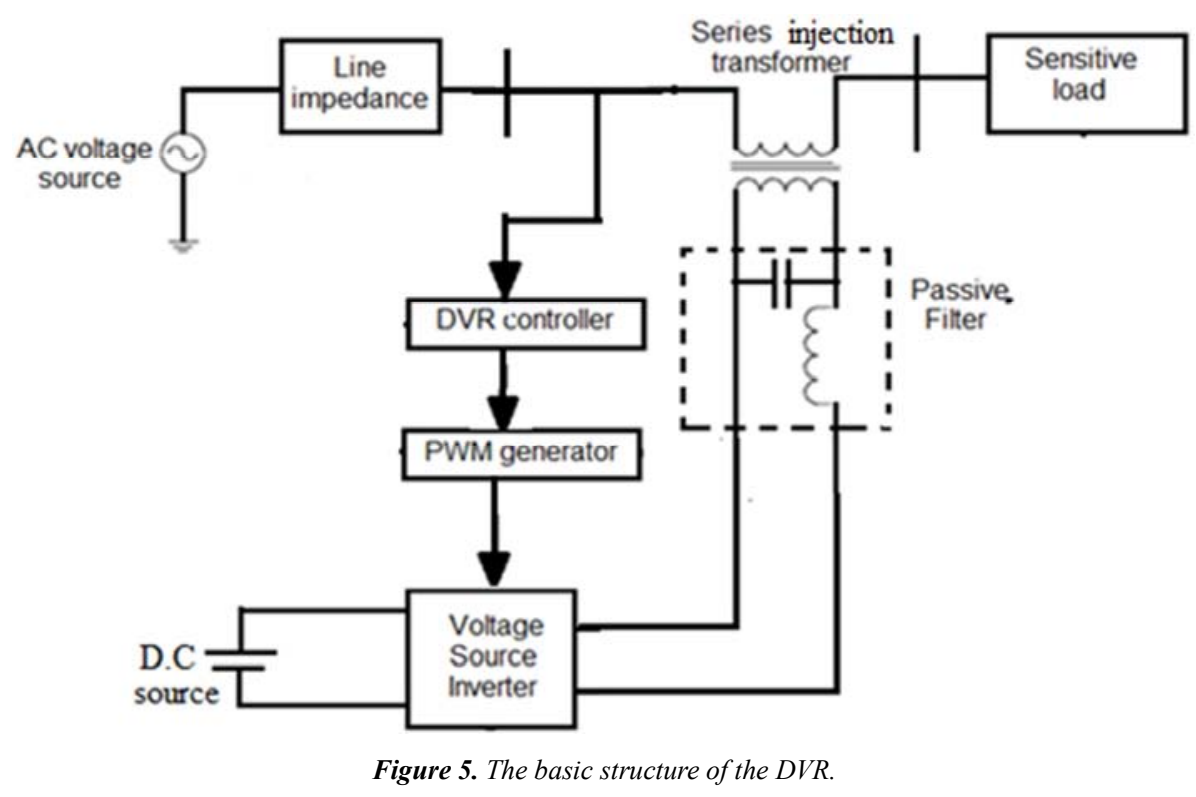

DVR essentially consists of a power circuit and a control system.

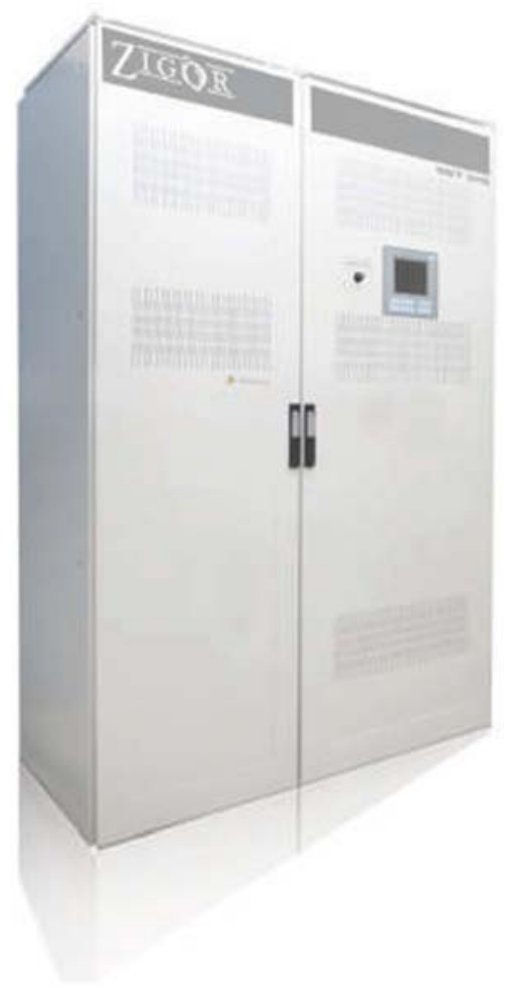

Figure 6. The DVR system. i) The power circuit of the DVR

The power circuit of the DVR consists of five main parts, energy storage unit, inverter circuit, pulse width modulation (PWM), passive filter and series injection transformer.

1- Energy Storage Unit

During a voltage disturbances the DVR injects a voltage to restore the load voltage to its nominal value, DVR needs sufficient energy for this compensation. In the literature different types of energy storage device are found. For instance, Battery energy storage system, Super capacitor, Flywheel energy storage, Wind energy and Solar energy[12]. In this work Battery energy storage system (BESS) is used because of the high stability for the (BESS). Lead acid batteries are popular due to its high response during charging and discharging. Also it is possible to provide the required energy on the DC side by bridge converter that is supplied from the AC source.

2- Inverter Circuit

Inverter is used to convert the DC voltage from energy storage device to a controllable three-phase $\mathrm{AC}$ voltages which is equal to the compensating voltage. The inverter in DVR must treat each phase independently due to a sag on one phase may lead to a swell on another phases therefore the (VSI) must be operate with unbalanced switching functions to handle both sag and swell simultaneously. In this work three level three phase inverter is used due to a high power and low harmonics at the output of this inverter 


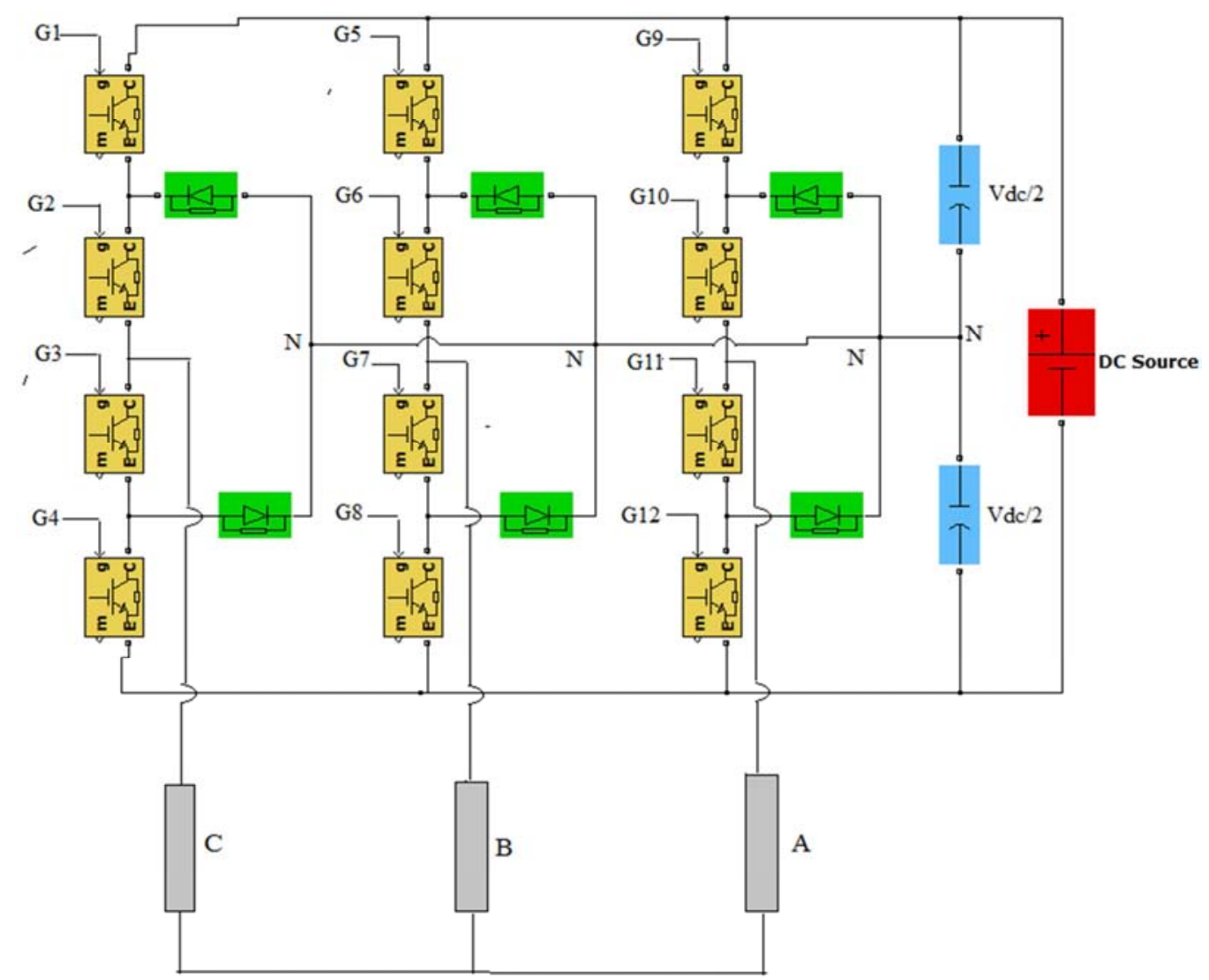

Figure 7. The electrical circuit of the three phase three level inverter.

\section{3- Pulse Width Modulation (PWM)}

PWM technique offers a good and a simplicity response also high switching frequencies can be used to improve the efficiency of the inverter without incurring high switching losses. There are several types of modulation technique used in DVR system such as hysteresis, PWM, deadbeat control and SVPWM (Space vector pulse width modulation)[13]. In this paper sinusoidal PWM is used which involves the comparison of reference waveform(modulating signal) with a triangular wave (carrier wave) of higher frequency in order to get a desired output voltage. Sinusoidal pulse width modulation (SPWM) has higher operating frequency capability and a great impact on its transient performance[14]. (SPWM) are widely used now days to generate gating signals in custom power devices.

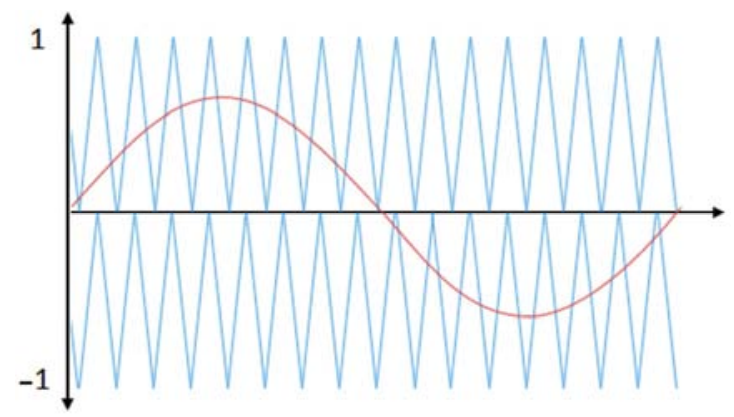

Figure 8. The PWM pulse generator for one arm of the three phase three level inverter.
4- Passive Filter

The filter unit consists of inductors and capacitors. It eliminates the high frequency harmonics at the inverter output, these harmonics are due to the non-linear characteristics of semiconductor devices. The filters can be positioned either in a low voltage side (inverter side) or in a high voltage side (line side). The distorted and harmful effects of harmonics produced by the inverter can be reduced using the inverter side and the line side. In this paper the inverter side filtering is proposed to prevent the high order harmonics from penetrating into the injection transformer and reduce the voltage Stress on the series transformer [15].

5- Series Injection Transformer

The main function of the injection transformer is increasing the injected voltages and getting an electrical isolation between the inverter and the network. The injected voltages are introduced by the injection transformer into the system in order to ensure the effectiveness and maximum reliability of this restoration scheme. The primary winding of the transformer must be connected to the inverter side while its secondary winding must be connected to the distribution network. To integrate the transformer correctly into the DVR, the following issues must be carefully addressed, turn ratio, MVA rating, primary and secondary windings, voltage and current rating. The primary of the three phase injection transformer connected using (delta) connection windings to eliminate the $3^{\text {rd }}$ harmonic and the secondary is connected using (open star) to connect the DVR in series with the 
distribution network [16].

ii) The control system of the DVR

Control strategy of DVR plays an important role in its performance [17]. The incorrect injection or the delay in the process would be dangerous to sensitive loads. The major functions of the DVR controller are, detection of voltage disturbances events in the system, calculation of the compensating voltage and generation the reference signal for the PWM to trigger the voltage source inverter [18]. The DVR controller in this paper consists of several functional blocks as depicted in Figure 9.

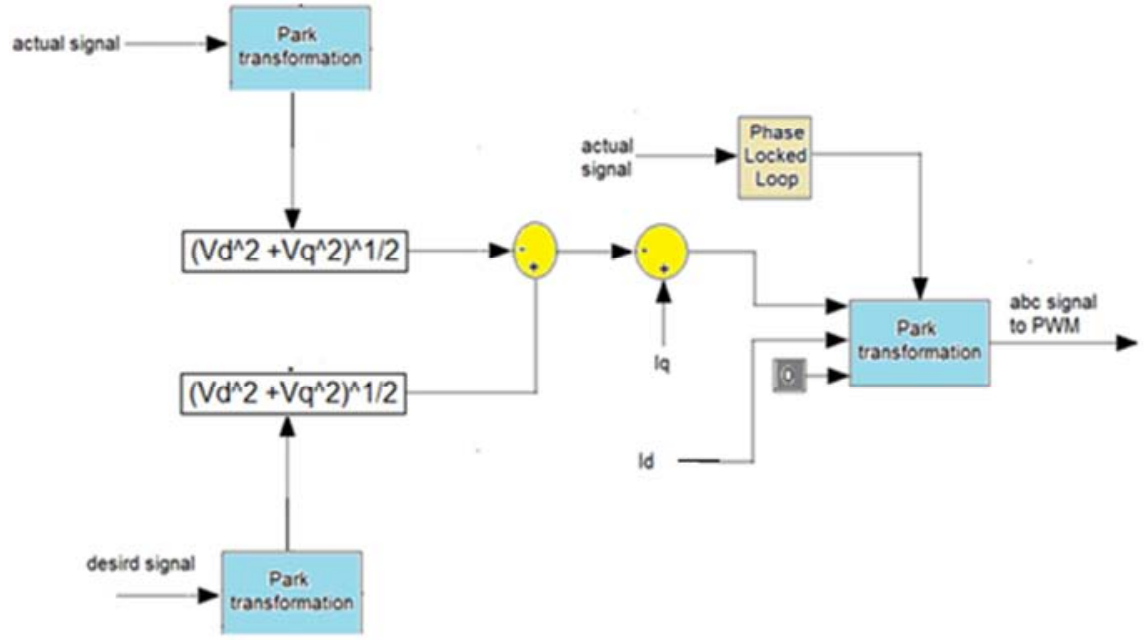

Figure 9. The control system of the DVR.

These functional blocks are:

1- The Phase Locked Loop (PLL) which is shown in Figure 10. It is synchronized to the fundamental of the transformer primary voltages

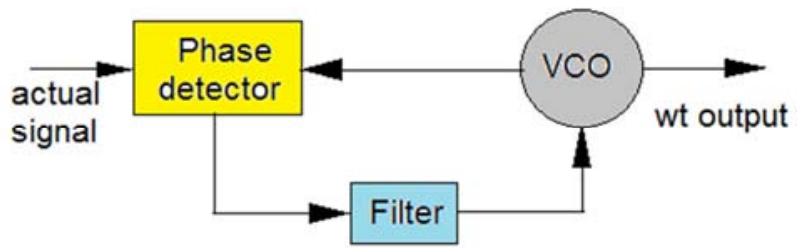

Figure 10. The Phase Locked Loop.

2- Park transformation transforms the three AC quantities $\left(\mathrm{V}_{\mathrm{a}}, \mathrm{V}_{\mathrm{b}}, \mathrm{V}_{\mathrm{c}}\right)$ to two DC quantities $\left(\mathrm{V}_{\mathrm{d}}, \mathrm{V}_{\mathrm{q}}\right)$ to simplify the calculations, control, and analysis [18].

$$
\begin{aligned}
{\left[\begin{array}{lll}
d & q & 0
\end{array}\right]=} & \sqrt{\frac{2}{3}}\left[\cos (\theta) \cos \left(\theta-\frac{2 \pi}{3}\right) \cos \left(\theta+\frac{2 \pi}{3}\right)\right. \\
& -\sin (\theta)-\sin \sin \left(\theta-\frac{2 \pi}{3}\right)-\sin (\theta \\
& \left.\left.+\frac{2 \pi}{3}\right) \sqrt{\frac{1}{2}} \sqrt{\frac{1}{2}} \sqrt{\frac{1}{2}}\right][a b c]
\end{aligned}
$$

3-Two measurement systems. $\mathrm{V}_{\text {meas }}$ and $\mathrm{I}_{\text {meas }}$ blockes.

$$
\begin{gathered}
\mathrm{V}_{\text {meas }}=\sqrt{(V d)^{2}+(V q)^{2}} \\
\mathrm{I}_{\text {meas }}=\sqrt{(I d)^{2}+(I q)^{2}}
\end{gathered}
$$

4- Inner loop for regulating the current, this loop consists of one controller which controls the q-axis current. The controller output is $\mathrm{V}_{\mathrm{q}}$ voltage. The $\mathrm{V}_{\mathrm{d}}$ and $\mathrm{V}_{\mathrm{q}}$ voltages are converted into phase voltages $\mathrm{V}_{\mathrm{a}}, \mathrm{V}_{\mathrm{b}}, \mathrm{V}_{\mathrm{c}}$ which are used to synthesize the PWM voltages. The $\mathrm{I}_{\mathrm{q}}$ reference comes from the outer voltage regulation loop

5- An outer voltage regulation loop consists of one controller to regulate the voltage.

\section{The Location of the DVR}

The connection of the DVR in the distribution system is either at medium voltage $11 \mathrm{Kv}$ as shown in Figure 11 or at low voltage $0.4 \mathrm{Kv}$ as shown in Figure 12

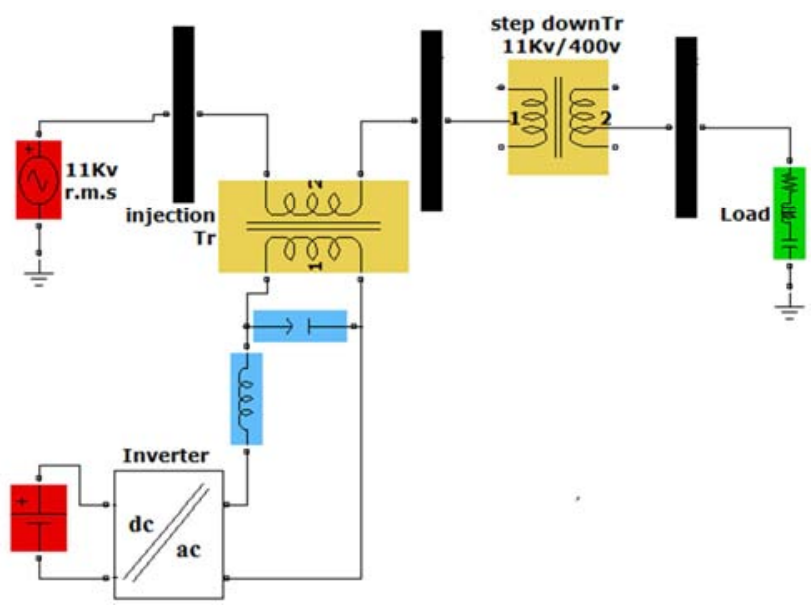

Figure 11. The location of the DVR at medium voltage. 


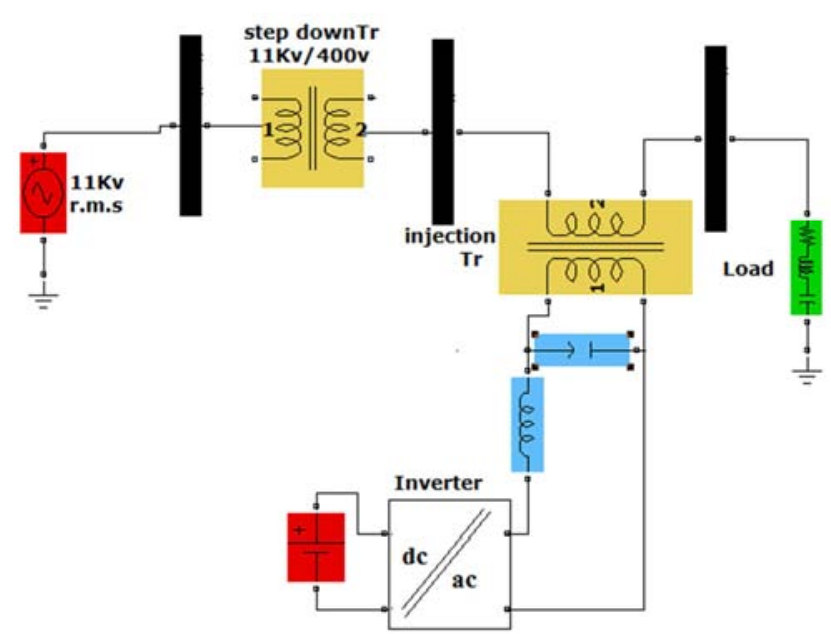

Figure 12. The location of the DVR at low voltage.

\section{Dynamic Voltage Restorer Based on Fuzzy Neural Optimized Fuzzy Logic Controller}

In general, there are no standard method for transforming human knowledge to the rules base of the fuzzy inference system. The selection of the type, size and parameters of the membership functions has been achieved by trial and error.
Therefore there is a real need to an effective method of tuning the input and output membership functions and reducing the rules to a minimum rules[17]. Fuzzy Neural Optimized Fuzzy Logic Controller (ANFIS) is a combined between a fuzzy qualitative approach and adaptive learning abilities of the neural network, where this system can be trained without a significant amount of expert knowledge that usually required for the standard FL. Jang in 1993 introduced Adaptive Neuro Fuzzy Inference System and mentioned that the (ANFIS) architecture can be utilized to model non-linear functions in control systems[18]. ANFIS uses a sugeno-type fuzzy inference system. ANFIS requires for training a set of input and output data, it can choose the parameters of the fuzzy inference system adaptively from the training data[19]. It produces a set of membership functions to map the input data to output. This sugeno fuzzy model has two inputs and one output and the ANFIS used here contains 9 rules with 3 membership functions for error and change of error for each controller. 10000 training data are used for the training of ANFIS and 1000 checking data are used for verifying the identified ANFIS. In this thesis the advantagesof the ANFIS will be defined in modeling and controlling of a non-linear system.

Figure 13 demonstrated the flow chart of the ANFIS algorithm and Figure 8 shows the structure of the ANFIS.

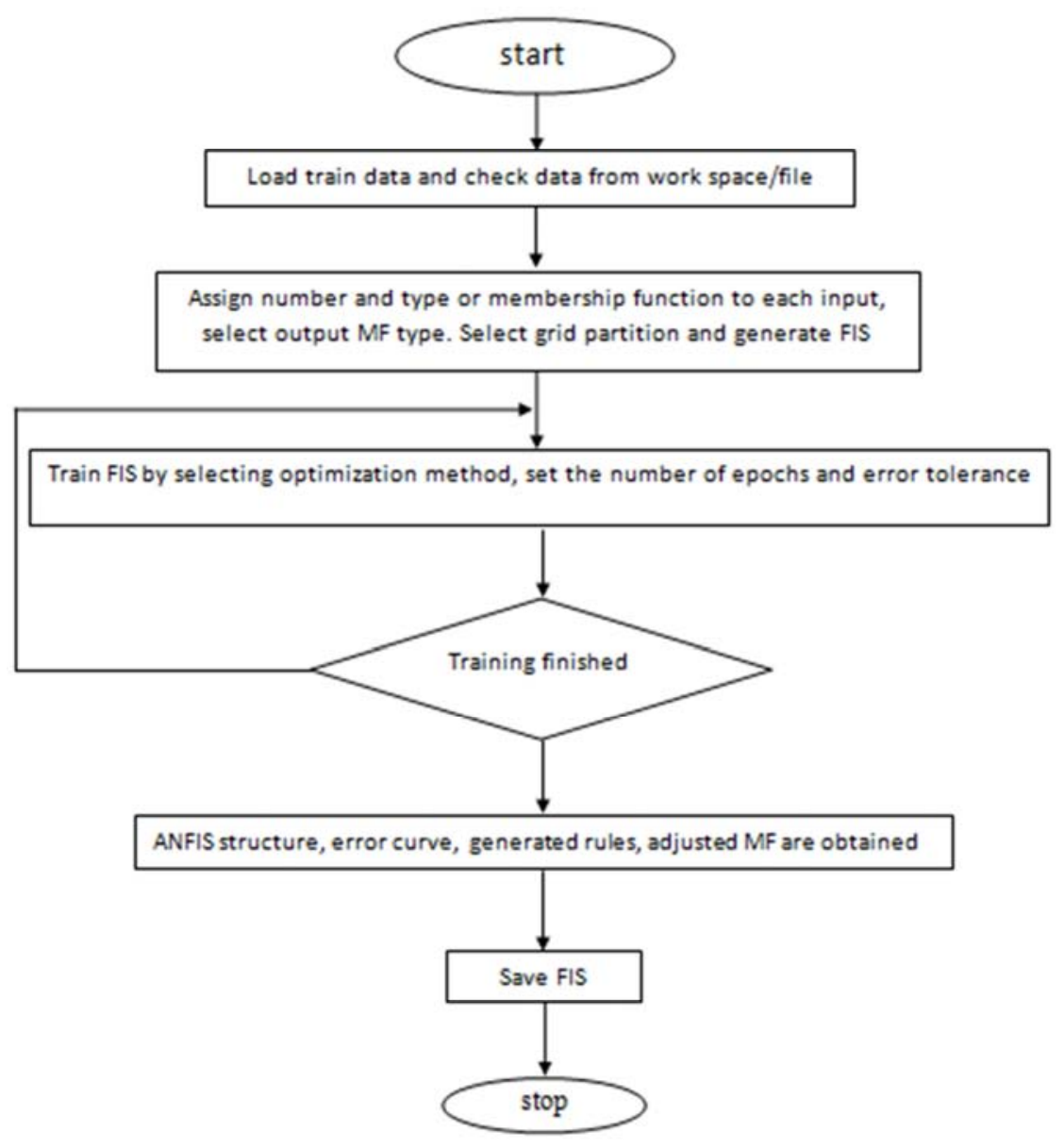

Figure 13. The flow chart of the ANFIS [12]. 


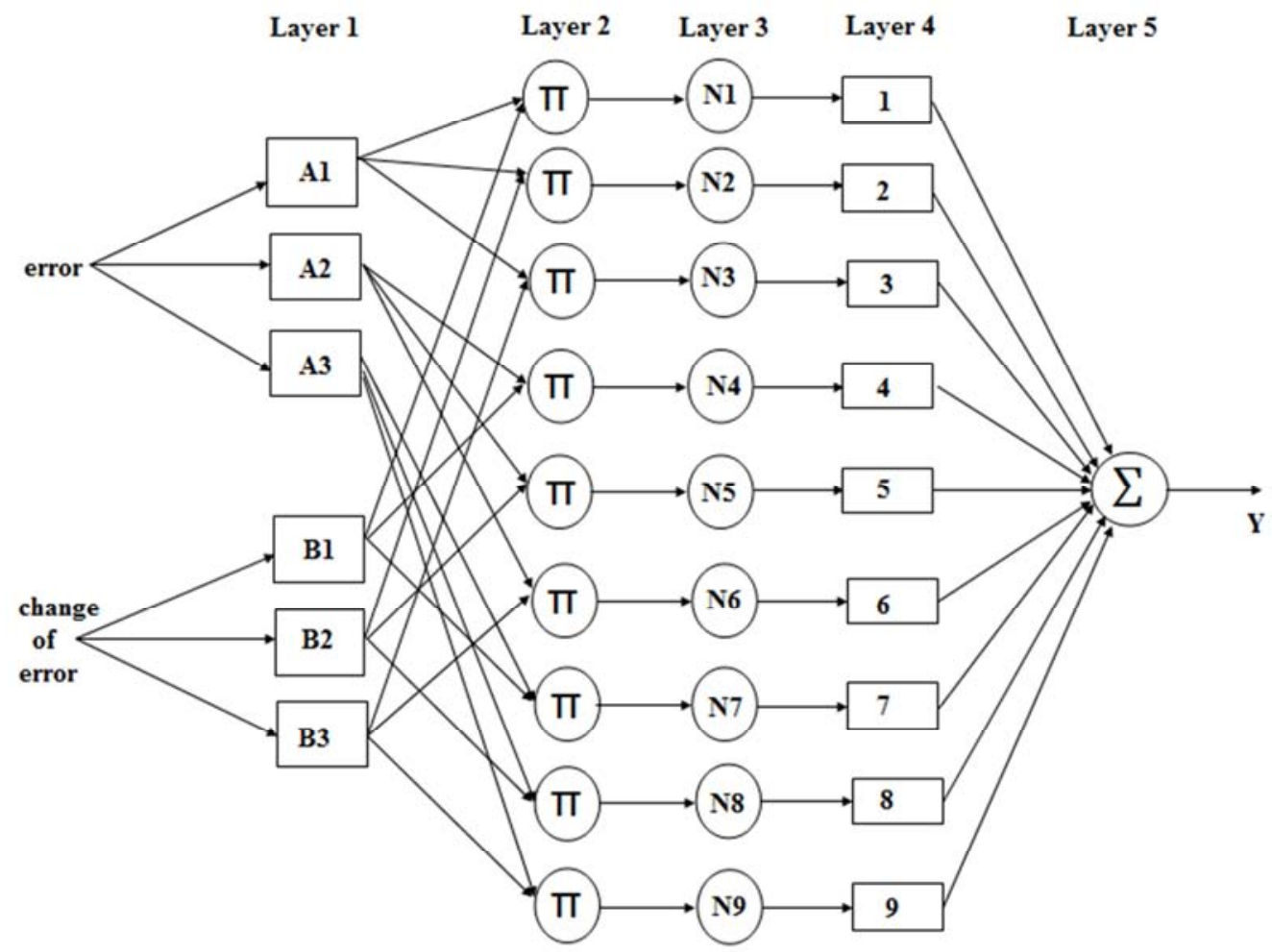

Figure 14. The structure of the ANFIS optimized Fuzzy Logic controller.

It is depicted from the figure above that the ANFIS has five layers. The basic principle of these layers are as following

Layer 1: It is called fuzzification layer and it has six nodes each node is adaptive to an output. If the membership functions in this layer is a triangular function, then the output from each node in this layer is obtained from the equations of the triangular function

$$
\begin{gathered}
\mathrm{A}(\mathrm{x})=\left\{\alpha\left(\frac{x-a}{c-a}\right) \text { if } a \leq x \leq c \alpha\left(\frac{x-b}{c-b}\right) \text { if } c \leq x \leq\right. \\
b 0 \text { otherwise }\}
\end{gathered}
$$

Where the $a, b, c$ is the parameter of the triangular function and $\alpha$ is the cut set as shown in Figure 15

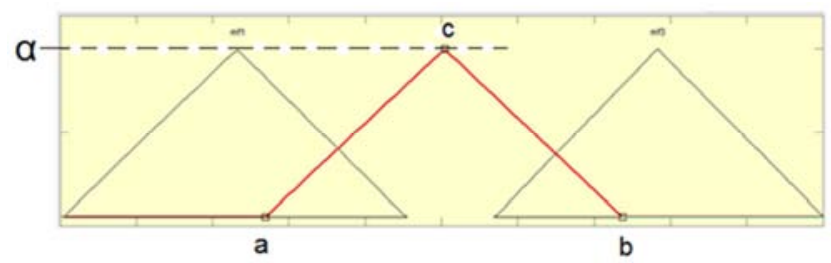

Figure 15. The triangular membership function.

The parameters a, b, c in this layer is known as premise parameter. This layer is calculating the grade of the membership for each input $\left(\mu_{\mathrm{Ai}}(\mathrm{x})\right)$

Layer 2: It determines the firing strength for each rule. It has nine nodes(equal to the number of rules). This layer is multiplying the incoming signals from the previous layer and forward to the next layer
The output from second layer for each node

$$
\mathrm{O}^{2} \mathrm{i}=\mathrm{Wi}=\mu_{\mathrm{Ai}}(\mathrm{x}) * \mu_{\mathrm{Bi}}(\mathrm{y})
$$

Layer 3: It calculates the normalized firing strength for each rule and the output from each node in this layer is equal to the ratio between the firing strength of this node and the summation of all nodes's firing strength

The output from each node in third layer

$$
\mathrm{O}^{3} \mathrm{i}=\mathrm{Wni}=\frac{W i}{\sum_{j=1}^{j=9} W j}
$$

Layer 4: It determines the output for each rule. Each node in this layer is an adaptive to an output. The output from each node in this layer is obtained by multiplying between the incoming signal from third layer and the set of parameters. Output from each node in the forth layer

$$
\mathrm{O}^{4} \mathrm{i}=\mathrm{Wni} * \mathrm{fi}=\mathrm{Wni} *\left(\mathrm{p}_{\mathrm{i}} \mathrm{x}+\mathrm{s}_{\mathrm{i}} \mathrm{y}+\mathrm{t}_{\mathrm{i}}\right)
$$

where ( $p, s$ and $t)$ are the parameters for each node and it is called the consequent parameters.

Layer 5: This layer is determining the output $\mathrm{o} / \mathrm{p}$ by summing the all incoming signals from the forth layer

$$
\mathrm{O} / \mathrm{P}=\sum_{i=1}^{i=9} \quad W n i * f i
$$

\section{Modeling and Simulation}

Figure 16 shows the non-linear loads have been connected to the electrical power source. Double tuned filter which has been tunned at $5^{\text {th }}$ and $7^{\text {th }}$ harmonics helps the DVR in 
mitigating the THD under non-linear loads. The efficiency and the capability of the fuzzy neural optimized fuzzy logic controller based DVR have been demonstrated by the simulation results under different fault conditions and power disturbances which are simulated at the first feeder for a periode of $0.15 \mathrm{~s}$ from $0.8 \mathrm{~s}$ and kept till $0.95 \mathrm{~s}$

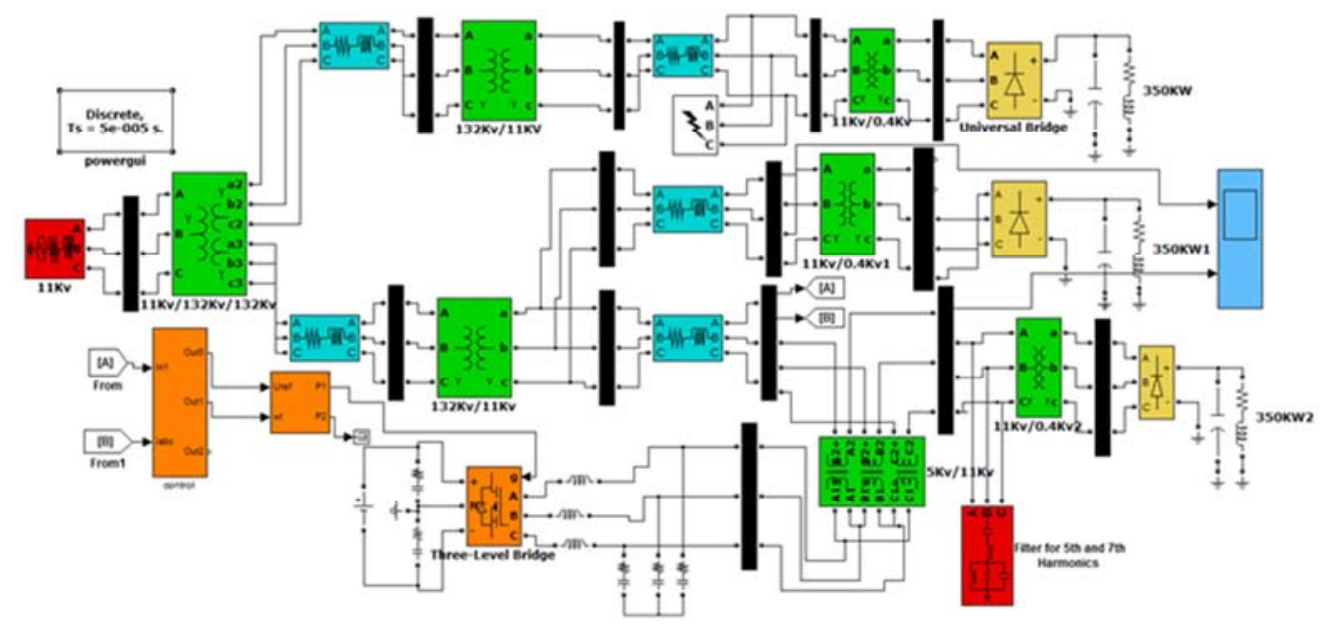

Figure 16. Modeling and simulation of the power system with DVR.

The parameters of the electrical power system with non-linear loads are demonstrated in table 1

Table 1. The parameters of the electrical power system with non-linear loads.

\begin{tabular}{ll}
\hline The parameters of the electrical power system & The values of the parameters \\
\hline The voltage source & $11 \mathrm{kV}$ r.m.s, $50 \mathrm{~Hz}$ \\
The transformer of the load & $11000 / 400 \mathrm{~V}_{\text {r.m.s }}, 412 \mathrm{KVA}$ \\
The DC source & $15000 \mathrm{v}$ \\
The active filter & $100 \mu \mathrm{F}, 300 \mathrm{mH}$ \\
The injection transformer & $5000 / 11000 \mathrm{~V}_{\text {r.m.s, }} 3 \mathrm{MVA}$ \\
The electrical load & $350 \mathrm{KW}, 50 \mathrm{~Hz}, 400 \mathrm{v}, 0.85 \mathrm{pf}$ \\
The fault resistance & $0.001 \mathrm{ohm}$ \\
The ground resistance & 0.001 ohm \\
Double tuned filter & Tuned at $5^{\text {th }}$ and $7^{\text {th }}$ harmonics, Q $=1.25 \mathrm{MVAR}$ \\
\hline
\end{tabular}

The control system of the DVR based on Fuzzy Neural optimized Fuzzy Logic controller is depicted in Figure 17.

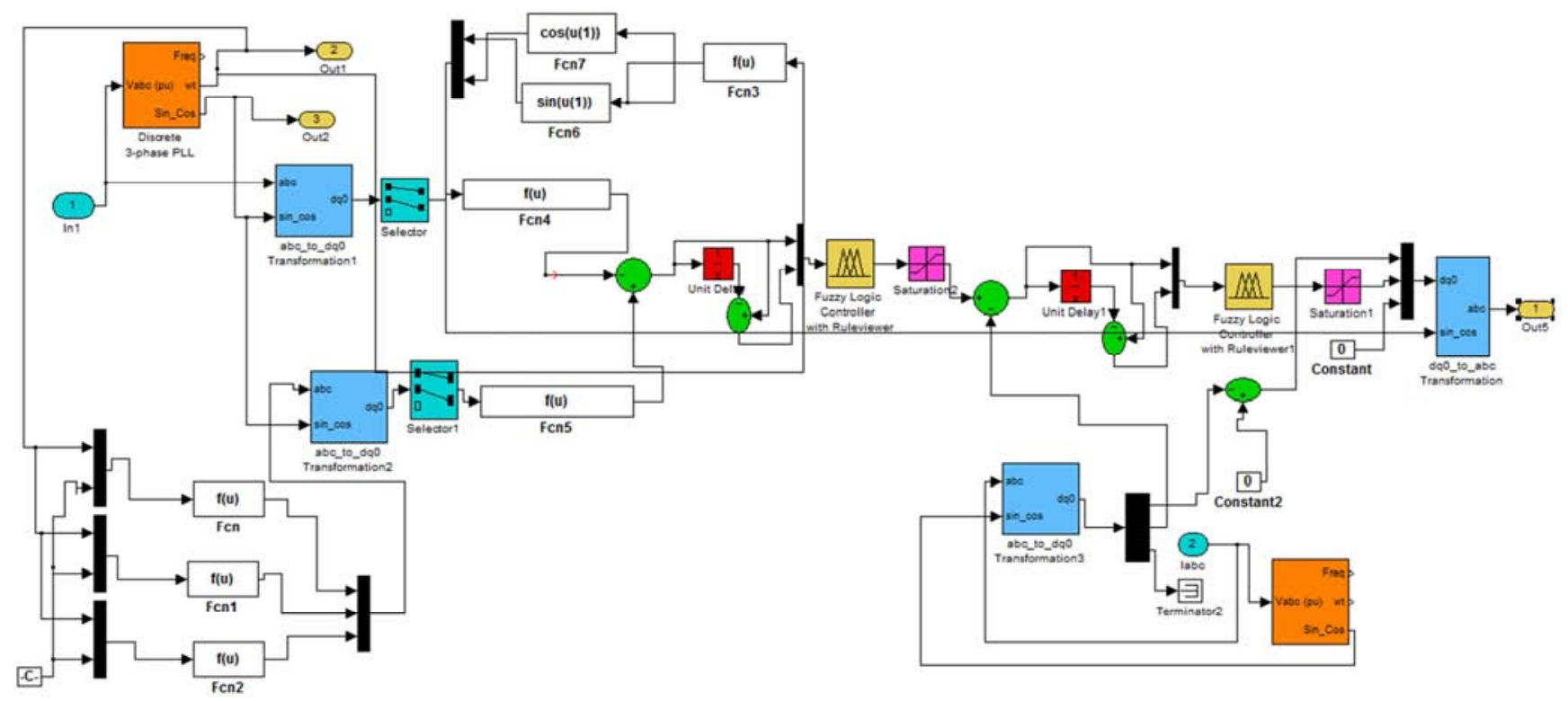

Figure 17. Modeling and simulation the control system of the DVR based on Fuzzy Neural optimized Fuzzy Logic controller.

In the electrical power system shown in Figure 16 single line to ground fault in the first feeder has no effect on the adajacent feeders, while double line to ground fault and three phase fault cause symmetrical and unsymmetrical sag 
respectivity as demonstrated in simulation results below. Fuzzy neural controller based DVR returns the load voltage to its correct form and mitigates the THD to an acceptable values as shown in figures below and determined in table. 2 Case-1: Single line to ground fault.

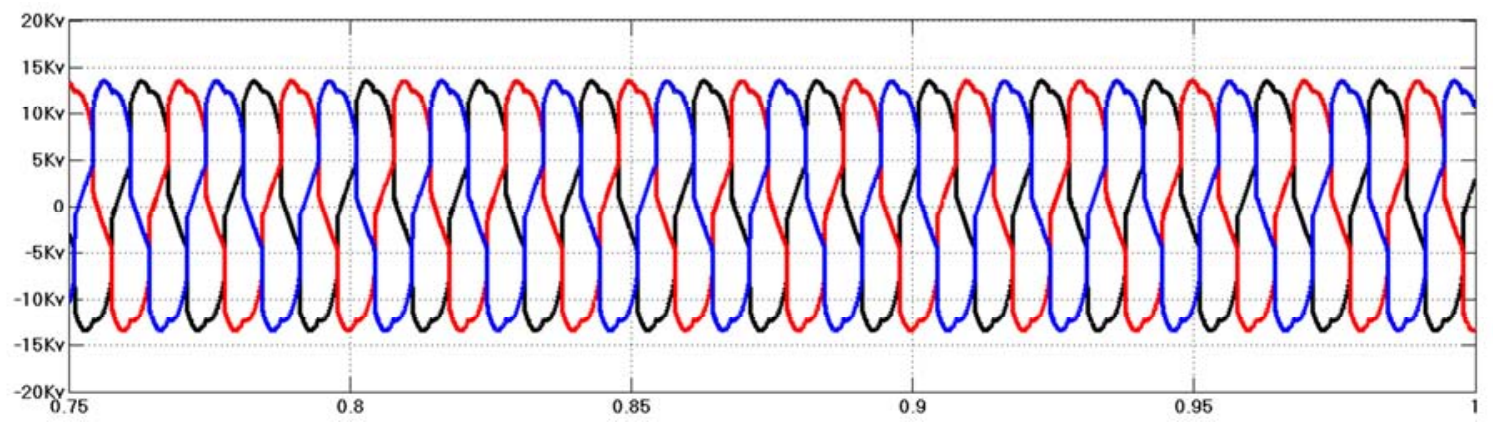

Figure 18. The load voltage at the second and third feeders without DVR.

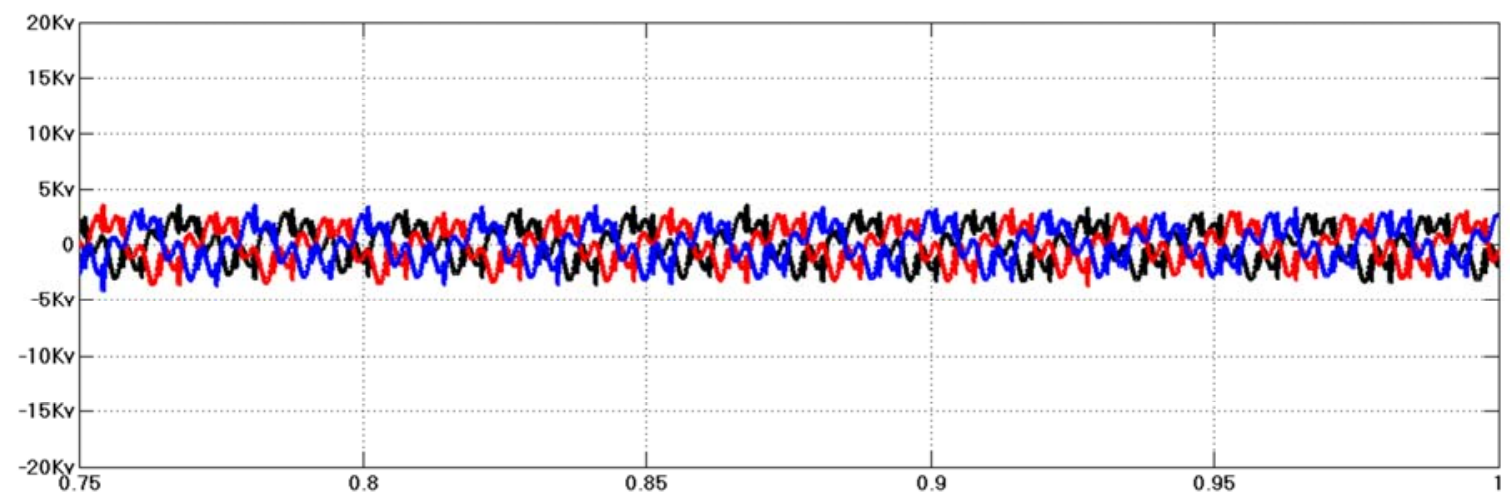

Figure 19. The voltage injected by the DVR.

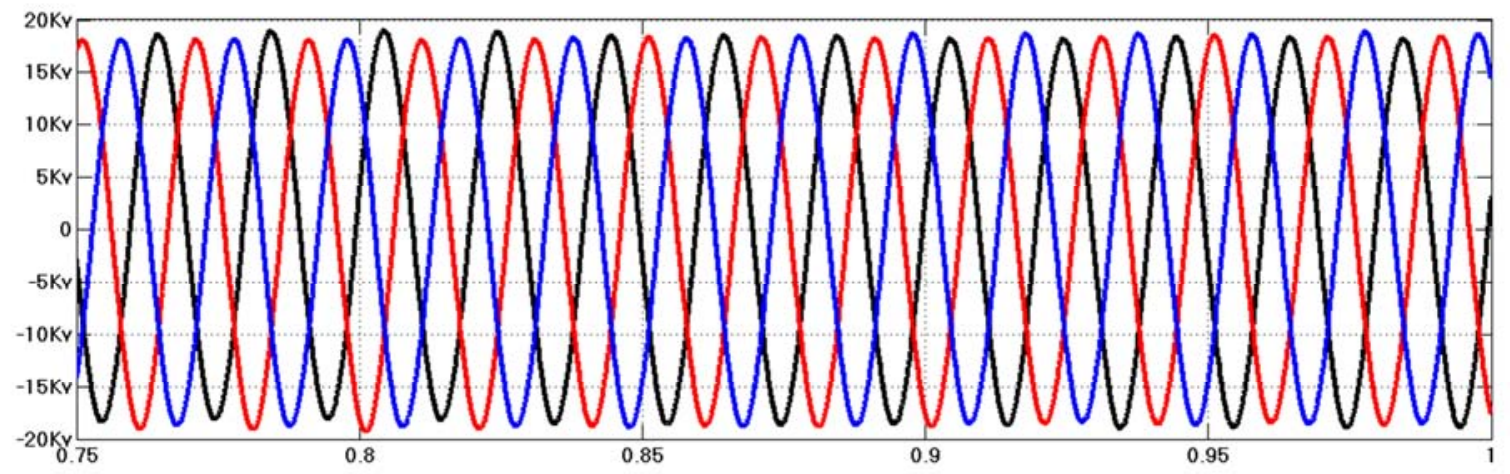

Figure 20. The load voltage at the third feeder with DVR based on Fuzzy Neural controller.

Case-2: Double line to ground fault

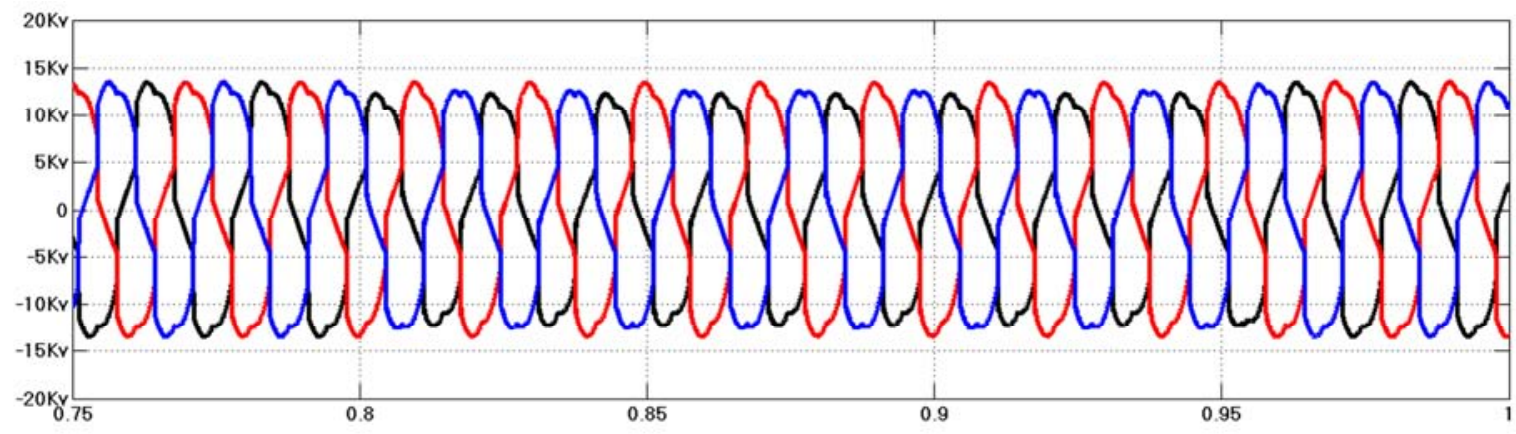

Figure 21. The load voltage at the second and the third feeders without DVR. 


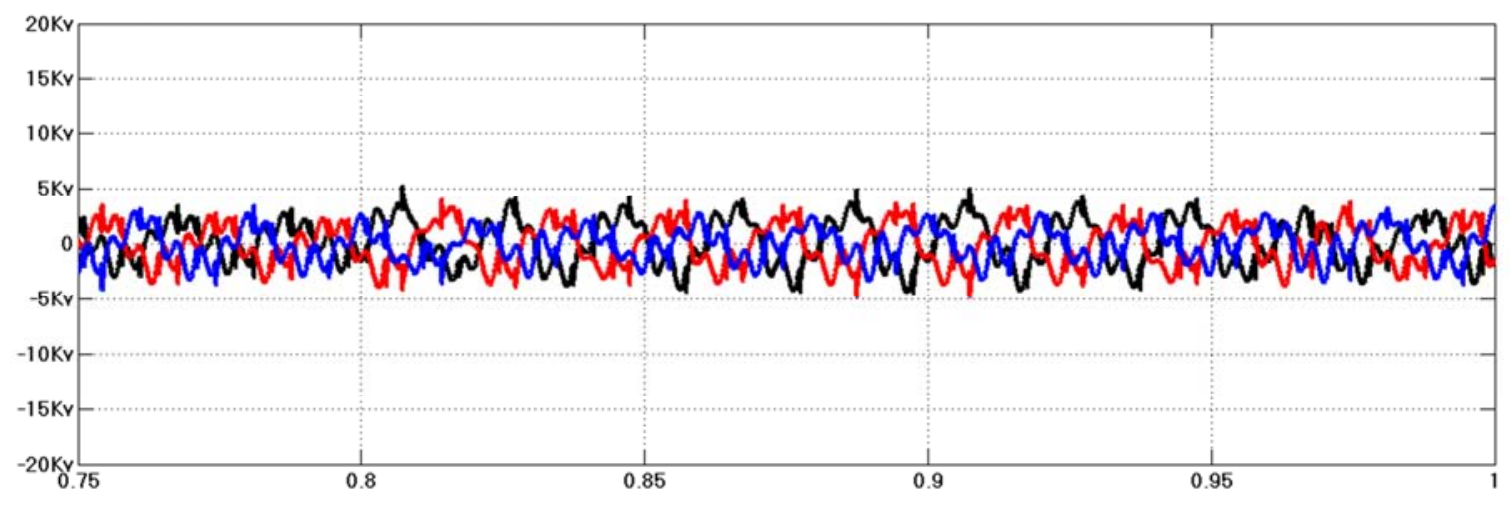

Figure 22. The voltage injected by the DVR.

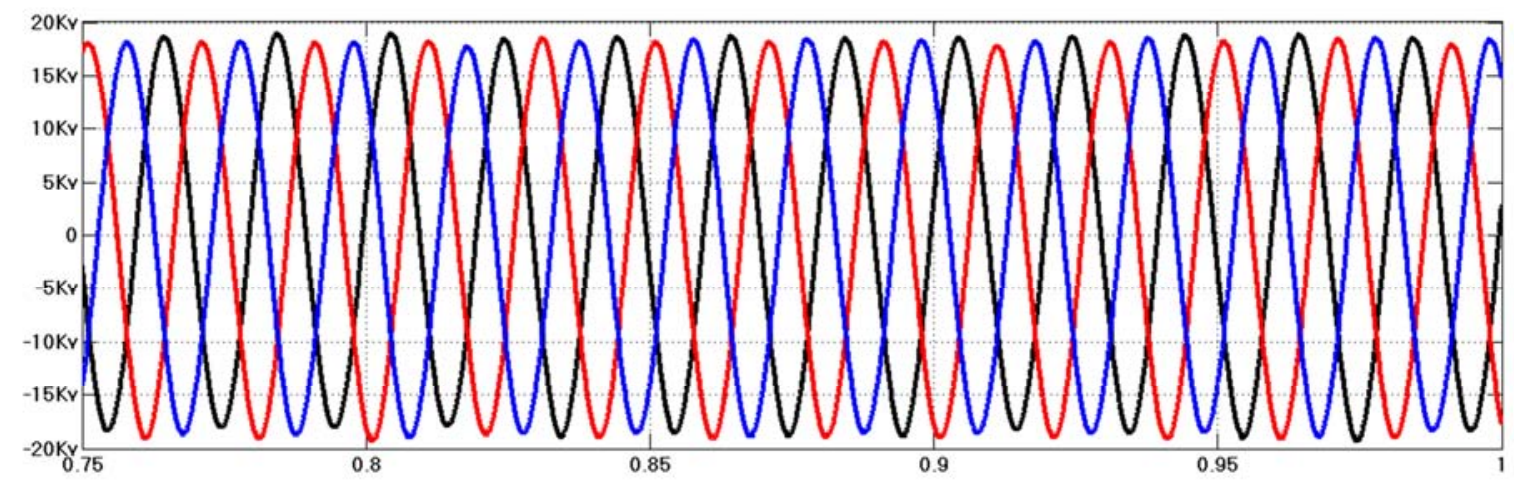

Figure 23. The load voltage at the third feeder with DVR based on Fuzzy Neural controller.

Case-3: Three phase fault

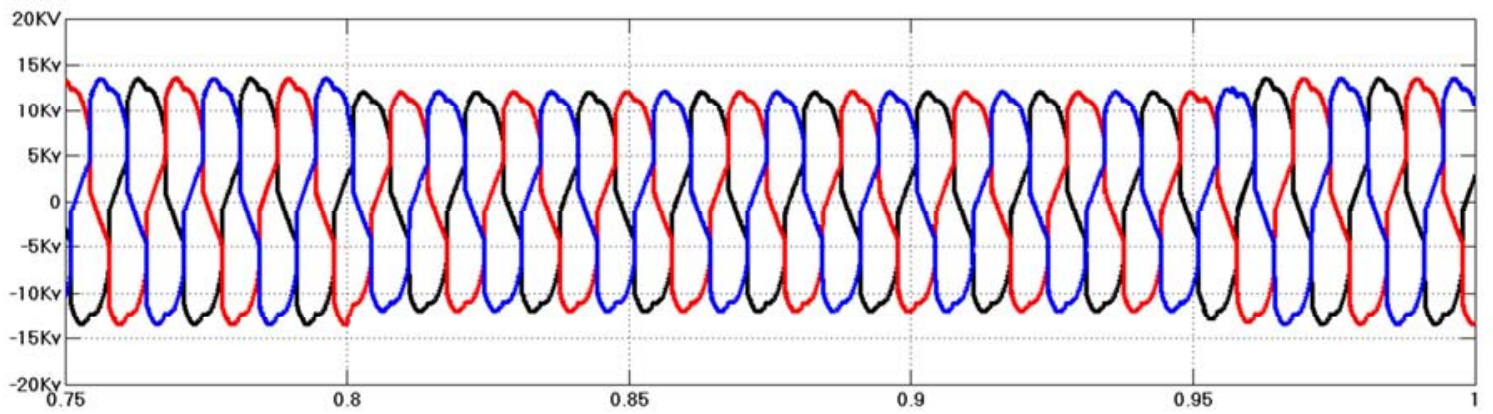

Figure 24. The load voltage at the second and the third feeders without DVR.

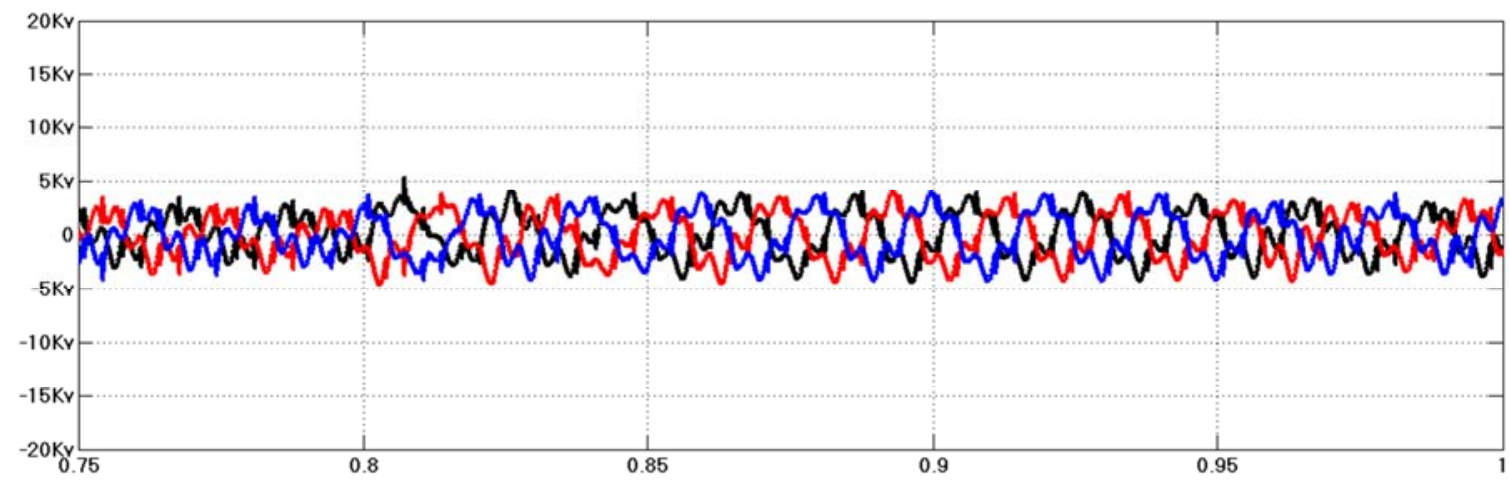

Figure 25. The voltage injected by the DVR. 


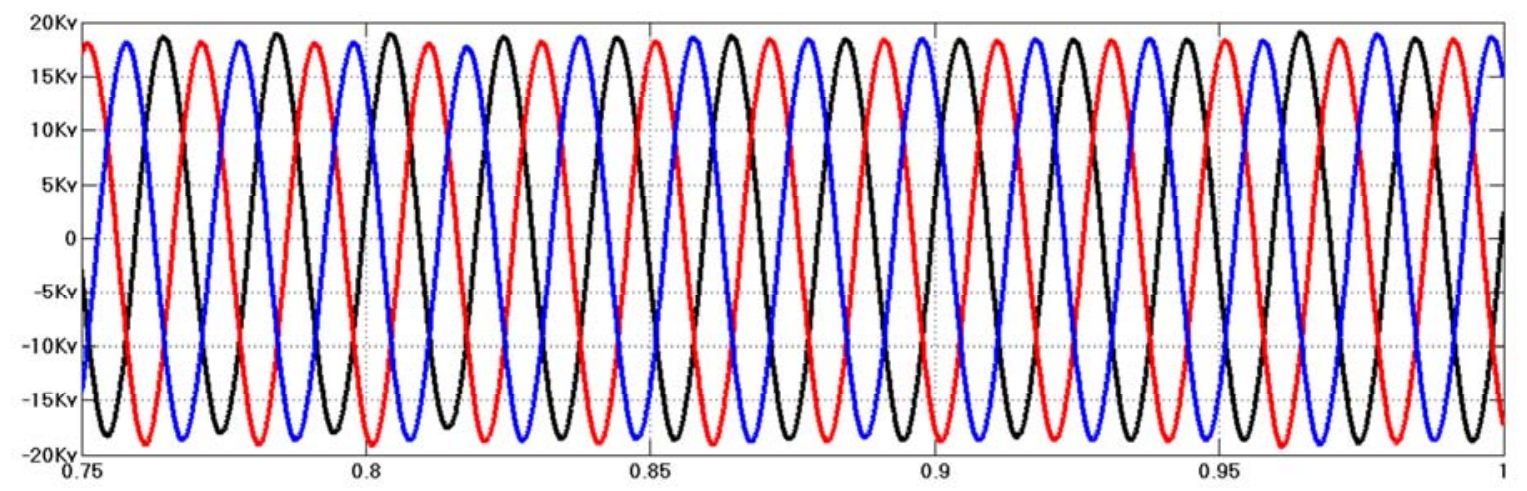

Figure 26. The load voltage at the third feeder with DVR based on Fuzzy Neural controller.

\section{The Total Harmonics Distortion of the Load Voltage}

The Total Harmonics Distortion is an important indication used for analyzing the power quality. The definition of THD is given by Hung T. Nguyen et al [20]

$$
\mathrm{THD}_{\mathrm{vp}}=\frac{\sqrt{\sum_{n=2}^{\infty} v_{p n}^{2}}}{v_{p 1}} \times 100
$$

Where $\mathrm{p}$ is the phase order and $\mathrm{n}$ is the harmonic order The THD can be calculated as follows:

$$
\mathrm{THD}=\frac{T H D_{v a}+T H D_{v b}+T H D_{v c}}{3}
$$

Table 2. The total harmonics distortion (THD) of the load voltage.

\begin{tabular}{lll}
\hline $\begin{array}{l}\text { The type of the } \\
\text { fault }\end{array}$ & $\begin{array}{l}\text { Load voltage } \\
\text { without DVR }\end{array}$ & $\begin{array}{l}\text { Load voltage with DVR based } \\
\text { on Fuzzy-neural controller }\end{array}$ \\
\hline Single-line fault & $17.683 \%$ & $0.99 \%$ \\
Double-line fault & $16.296 \%$ & $1.346 \%$ \\
Three-phase fault & $16.64 \%$ & $1.103 \%$ \\
\hline
\end{tabular}

\section{Conclusions}

The custom power devices are used to improve the power transfer capabilities and stability margins of the transmission line. DVR is the most effective in restoring the sensitive load voltage to the pre-fault value and make it smooth under different cases of faults and nonlinear load conditions. The proposed DVR handles different power disturbances without any difficulties and injects the appropriate voltage components to correct any fault situation that occurred in the electrical grid to keep the load voltage balanced and constant at the nominal value. Artificial intelligent especially the adaptive methods such as Fuzzy Neural optimized Fuzzy Logic controller is a better way to solve the non-linear system control problems since they have a parallel processing and learning capabilities, hence it has received considerable attention in the field of controller design. By using the ANFIS algorithm we can embed empirical information and expert into the fuzzy system, and this greatly expands and enhances the range of applications of fuzzy systems. The Double tuned filter with a value of $\mathrm{Q}=1.25 \mathrm{MVAR}$ is used to help the DVR in mitigating the THD from a high value to less than $3 \%$ under different fault conditions with non-linear loads.

\section{References}

[1] Dixon, JG, Venega, SG \& Moran, LA 1997, 'A series active power filter based on a sinusoidal current controlled voltage source inverter', IEEE Transaction on Industrial Electronics, vol. 44, no. 5, pp. 612-620.

[2] M. I. Marei, E. F. EI-Saadany, and M. M. A. Salama, "A new approach to control DVR based on symmetrical components estimation," iEEE Trans. Power Del., vol. 22, no. 4, pp. 20172024, Oct. 2012.

[3] "'IEEE Recommended Practices and Requirements for Harmonic Control in Electrical Power Systems New York NY: IEEE", IEEE Std 519-1992.

[4] Newman, MJ, Holmes, DG, Nielsen, JG \& Blaabjerg, F 2005, 'A dynamic voltage restorer (DVR) with selective harmonic compensation at medium voltage level', IEEE Transaction on Industry Applications, vol. 41, pp. 1744-1753.

[5] Nielsen, JG \& Blaabjerg, F 2005, ' A detailed comparison of system topologies for dynamic voltage restorer', IEEE Transactions on Industrial Applications, vol. 41, no.5, pp. $1272-1280$.

[6] Salimin, RH \& Rahim, MSA 2011, 'Simulation analysis of DVR performance for voltage sag mitigation', Proceedings of IEEE Power Engineering and Optimization Conference (PEOCO), pp. 261-266

[7] F. A. L. Jowder, "Design and analysis of dynamic voltage restorer for deep voltage sag and harmonic compensation", IET Gener. Transm. Distrib., vol. 3, no. 6, pp. 547-560, 2009.

[8] M. N. Tandjaoui, et al., "Sensitive Loads Voltage Improvement Using Dynamic Voltage Restorer," International Conference on Electrical Engineering and Informatics, 2011. Conference publication. IEEE Xplore digital library

[9] C. Fitzer, A. Anulampalam, M. Barnes, and R. Zurowski "Mitigation of Saturation in Dynamic Voltage Restorer Connection Transformers ", IEEE Transactions on Power Electronics, Volume: 17, Issue: 6, Nov. 2002, pp. 1058 - 1066.

[10] J. G. Nielsen, F. Blaabjerg, N. Mohan, "Control strategies for dynamic voltage restorer compensating voltage sags with phase jump", Proc. IEEE/APEC'01 Conference, vol. 2, pp. 1267-1273, 2001. 
[11] J. Klapper, J. T. Frankle, Phase-Locked and FrequencyFeedback Systems, New York: Academic Press, 1972.

[12] J. G. Nielsen, Design and Control of a Dynamic Voltage Restorer, 2002.

[13] S. Aboulem, E. M. Boufounas, I. Boumhidi, "Optimal tracking and robust intelligent based PI power controller of the wind turbine systems", 2017 Intelligent Systems and Computer Vision (ISCV), pp. 1-7, 2017.

[14] S. Nayak, S. Gurunath, N. Rajasekar, "Advanced single-phase inverse park PLL with tuning of PI controller for improving stability of grid utility using soft computing technique", 2016 Online International Conference on Green Engineering and Technologies (IC-GET), pp. 1-5, 2016.

[15] H. A. Kazem, "Harmonic Mitigation Techniques Applied to Power Distribution Networks", Advances in Power Electronics, pp. 10, Jan. 2013.
[16] D. Chen, H. C. He, and H. Wang, "Fuzzy control technique based on continuous t-norm and s-norm," Control Theory and Applications, vol 18, no. 5, pp. 717-721, 2001.

[17] W. X. Zhang, G. X. Liang, Fuzzy control and system, Xi'an: Xi'an Jiaotong University Press, 1998, pp. 72-78.

[18] C. Benachaiba, B. Ferdi, "Voltage quality improvement using DVR", Electrical Power Quality and Utilization Journal, vol. XIV, no. 1, pp. 39-45, 2008.

[19] Jang JSR (1993) ANFIS: adaptive network-based fuzzy inference systems. IEEE Trans Sys Man Cybern 23:665-685.

[20] Hung T. Nguyen, Nadipuram R. Prasad Carol L. Walker, Elbert A. Walker. 'A First Course in FUZZY and NEURAL CONTROL', printed in the United States of America 1234567890 printed on acid -free paper; chapter. 2; pp. 88-90. 